\title{
LARGE-SCALE MAPPING OF AQUIFERS IN THE COUNTY OF AARHUS USING GEOPHYSICAL METHODS
}

\author{
Kurt I. Sørensen \\ Department of Earth Sciences, Aarhus University \\ Finlandsgade 8, 8200 Aarhus N., Denmark \\ and \\ Verner H. Søndergaard \\ Aarhus County, Environmental devision, Department of Ground Water and Raw Materials, \\ Lyseng Allé 1, 8270 Aarhus, Denmark
}

\begin{abstract}
INTRODUCTION
Increasing problems with water quality have made ground water a very important issue in Denmark. In 1995 the Minister of Environment decided a 10-subjects scheme to improve ground water protection. One of the major issues is that all pesticides that can pollute the ground water should be forbidden. Another major issue is that counties in Denmark by the end of 1997 should be classified into 3 types of recharge areas.

The classification includes: - Recharge areas of great drinking water interest,

- Recharge areas of drinking water interest and

- Recharge areas of limited drinking water interest

The clasciffication is based on a comprehensive evaluation of the size and quality of the ground water resource. The new ground water resource plan provides guide-lines for the protection of the ground water in the county.
\end{abstract}

The next step in the ground water protection scheme will be a classification in ground water protection zones based on detailed geological mapping and calculations by means of ground water models within the areas classified as recharge areas of great drinking water interest. The classification in protection zones and the guide-lines should be used to prevent ground water pollution from unwise location of new city development areas, to decide on possible clearings of old waste disposals, to make arrangements to reduce leaching of nitrate etc. The National Agency of Environmental Protection has decided to make a guide for this classification.

The detailed mapping based on the usage of a combination of geophysical methods and geological informations from existing water supply wells has demonstrated that a traditional mapping based only on drilling data is insufficient and without the details needed to set restricted guide-lines for land use.

The most important source of country-wide information on ground water conditions and aquifers is drilling information. More than 120,000 such drillings have been carried out and reported in Denmark since 1926. Although this appears at first glance to be quite a lot, it amounts to an average of less than 3 drillings per $\mathrm{km}^{2}$, including, of course, poorly documented drillings. Such drilling density allows only a very general description of the complex geological composition of the Danish aquifers.

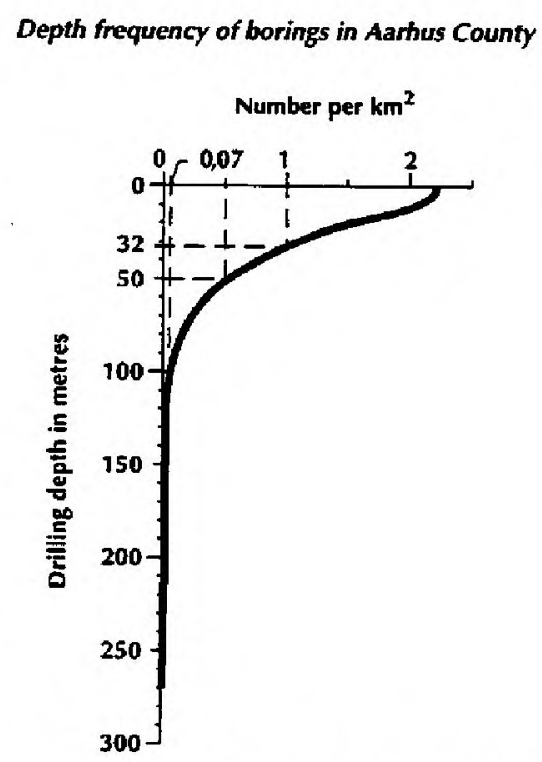

The figure shows that of the approx. 10,000 drillings in Aarhus County (area: $4,560 \mathrm{~km}^{2}$ ) $50 \%$ reach down to $30 \mathrm{~m}$ - the equivalent of one drilling per $\mathrm{km}^{2}$. Only one drilling per $15 \mathrm{~km}^{2}$ reaches down to at least $100 \mathrm{~m}$ 's depth! It is at this depth many of the most important aquifers in Denmark are to be found. 
Until a few years ago geophysical investigation methods had been used only in connection with very local cases concerning ground water conditions. The geoelectrical sounding method was the most commonly used method of investigation of ground water conditions up until the early nineties.

In recent years, new geophysical methods have been developed through a joint venture involving the University of Aarhus, the Public Utilities of Aarhus and the County of Aarhus. The new methods have been designed to upgrade and rationalise fieldwork, as well as regionalise the use of the mapping methods. These methods allow exactly the detailed mapping of aquifers that is needed today. [1]

The kind of mapping necessary involves so many aspects that one method of investigation alone will not suffice. Developments have therefore involved different types of mapping methods which are used to investigate different facets of aquifers: their extension, vulnerability and water quality.

The usage of the methods depends on the fact, that different electric formation resistivities are observed in sand and clay sediments. By way of electric and electromagnetic methods, aquifers of sand and gravel can be distinguished from surrounding impermeable layers of clay.

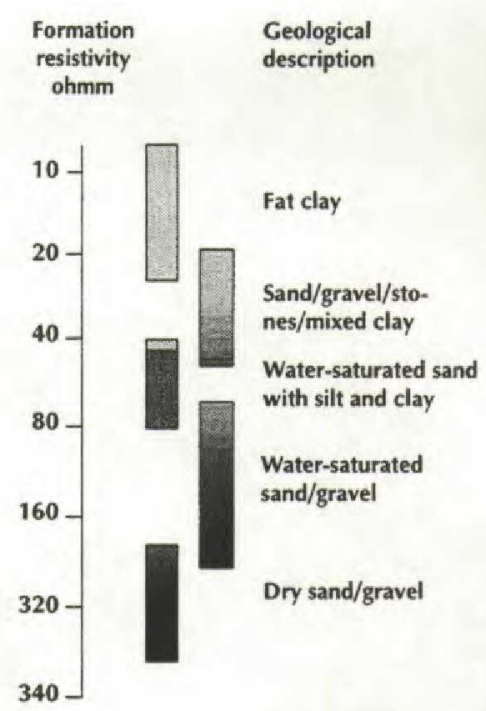

The figure shows the electrical formation resistivity for different Danish sediments. Formation resistivity is closely correlated with the hydraulic properties of the sediments.

The following examples will focus on the methods used when mapping the extension of aquifers and their water quality.

\section{The Extension of Aquifers}

Aquifers are often to be found in the tertiary clay substratum of bounded, eroded valleys. They can, to a greater or lesser degree, be interconnected. However it is important to know the regional structures and their interconnections in order to be able to assess potential possibilities for abstraction, to account regional resources and to point out key vulnerable land areas above aquifers.

The Transient Electromagnetic Sounding Method (TEM) has in recent years been introduced in connection with the mapping of larger structural geological pictures, and has provided extremely good results. The method maps out primarily those layers of clay, which demarcate the boundaries of the aquifers. Despite TEM only having been practised in Denmark for a limited amount of years, a substantial number of investigations have been carried out. The results have corresponded fully with the scattered drilling information which was available from the areas concerned. [2]

For the sake of the quality and interpretation of the data, the method requires dense measuring. It thereby also reveals the relatively heterogenous composition of most aquifers. This knowledge is a precondition for building up monitoring programmes and interpreting the monitoring results in a proper way. Heterogeneity is of great importance to the flowpattern of the ground water within an aquifer and thereby also to the interpretation of the quality of water which is observed on any location in the aquifer.

Around the city of Aarhus more than 5,000 Transient Electromagnetic Soundings have been carried out in an adjoining area of more than $400 \mathrm{~km}^{2}$ !. The high data density in this large area has produced a very detailed and coherent map of the interconnections between buried, prequartenary valleys. These interconnections are crucial for the understanding of extensions and interrelations of the aquifers in the area.

The next figure shows a map of the prequartenary clay surface around Aarhus based on interpretations from more than 5000 TEM-soundings. 


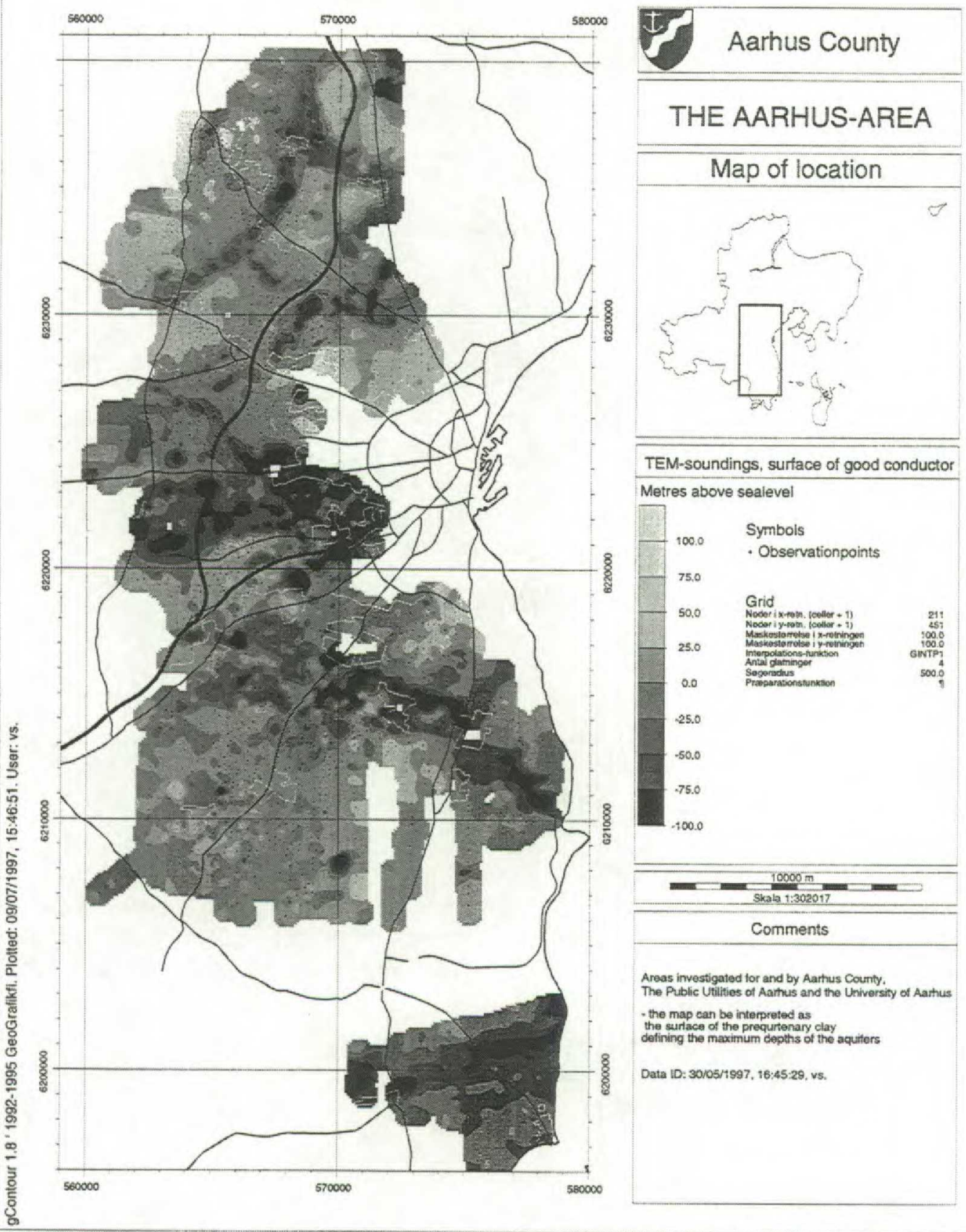

TEM-soundings in an area of more than $400 \mathrm{~km}^{2}$ around Aarhus reveal a system of buried valeys in the prequartenary clay surface. These valeys hold some of the most important aquifers in the area.

\section{Aquifer Water Quality}

In Denmark the aim is to avoid complex water treatment at water works. It is therefore necessary to obtain detailed knowledge of the quality and the variation in the quality of the water in the important aquifers. Otherwise, the location of abstraction wells and the distribution of abstractions can not be optimised. Likewise, this detailed knowledge is a precondition for the estimation and monitoring of water quality. It is however economically and practically impossible to gather knowledge of the detailed water quality distribution by means of traditional drilling methods.

A new Ellog Auger Drilling method has therefore been developed, whereby different log-measurements are made and level-specific water samples are taken during the actual drilling down.

A major advantage of using the new Ellog Auger Drilling method is, that the interplay between the variation in water quality and lithological conditions can be observed - an interplay which is important but seldom recognised in connection with traditional drilling techniques. [3] 
The method can be used to create a picture of the often very complicated water quality profile down through an aquifer.

As is shown below nitrate and other pollutants affect the ground water quality to considerable depths in areas with sandy "windows" in the clay cap covering the aquifers.

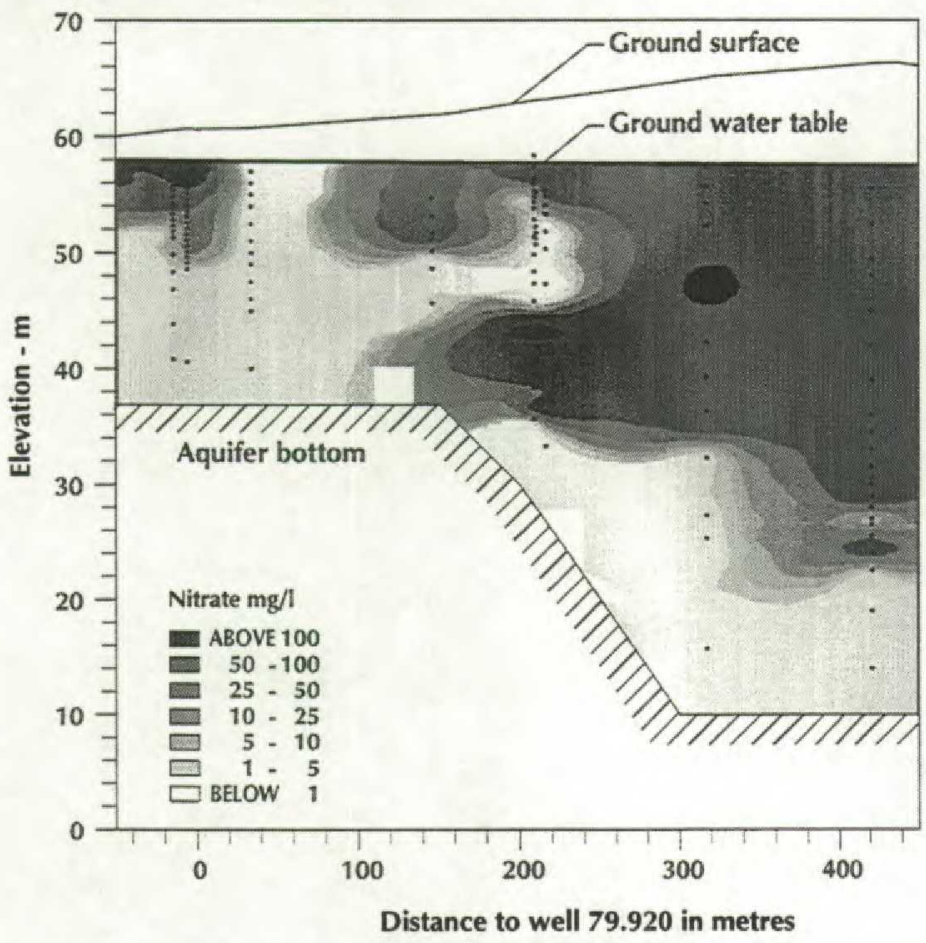

Nitrate at the Grundfor trace. With the Ellog Auger Drilling method water samples has been taken during the drilling in the saturated zone.

The nitrate have easy access to the aquifer through the sandy "window" in covering clay cap.

The effect of a sandy "window" is obvious.

\section{Conclusions and perspectives}

During the last $6-8$ years an intensive large-scale mapping of the aquifers by means of geophysical methods has been launched around Aarhus. A cooperation between the University of Aarhus, the Municipality of Aarhus and the County of Aarhus has lead to remarkable developments of methods and instruments concerning Transient Electromagnetic Soundings, Pulled Array Continuos Electrical Profiling and the Ellog Auger Drilling Method. Areas of more than $400 \mathrm{~km}^{2}$ in the Aarhus-region have been mapped with a high density of measurements by means of these geophysical methods resulting in the delineation of subsurface structures, that would probably not have been discovered without.

The combination of the large-scale geophysical mapping project and the important information from the national file of drillings will be the fundamental basis for the monitoring as well as for the protection of important ground water resources on which future drinking water supply of the Aarhus region has to be founded.

\section{References}

[1] Høeg, S., Pedersen, E., Sørensen, K.I., Søndergaard, V., Thomsen R., 1995: Water-supply. The Public Utilities of Aarhus, The University of Aarhus, and Aarhus County, Lyseng Allé 1, 8270 Højbjerg, Denmark.

[2] Christensen, N.B., and Sørensen, K.I., 1995: New strategies for surface and borehole electromagnetic methods in hydrogeophysical inverstigations. 1st Meeting of the EEGS European Section, Torino, Italy, 356-359. Enviromental and Engineering Geophysical Society, European section. P.O.Box 51, CH-1015 Lausanne, Switzerland.

[3] Sørensen, K.I., 1994: The Ellog auger Drilling Method. Proceedings of the Symposium on the Application of Geophysics to engineering and enviromental Problems, March 1994, Boston, Massachusetts, 985-994. Environmental and Engineering Geophysical Society, P.O. Box 4475, Englewood, CO 80155, USA. 